http://dx.doi.org/10.18542/rmi.v14i22.9642

\title{
O DISPOSITIVO PEDAGÓGICO DAS REVISTAS CONTIGO! E ROLLING STONE EM RELAÇÃO A PABLLO VITTAR
}

\author{
THE PEDAGOGICAL DEVICE OF THE MAGAZINES WITH YOU! AND ROLLING STONE \\ IN RELATION TO PABLLO VITTAR \\ Julian Junior dos Santos BARBOSA ${ }^{1}$ \\ Universidade Federal de Mato Grosso (UFMT) \\ Fernando ZOLIN-VESZ ${ }^{2}$ \\ Universidade Federal de Mato Grosso (UFMT)
}

Resumo: Este artigo analisa as edições n. $2.192 e$ 137 das revistas Contigo! e Rolling Stone, publicadas respectivamente em setembro de 2017 e janeiro de 2018. Tais revistas apresentam práticas linguísticas em relação à cantora Pabllo Vittar que parecem desestabilizar o binômio masculino-feminino, constituinte do que se convencionou denominar língua portuguesa. A construção do corpus de análise pauta-se na pesquisa documental, sendo formado por quinze excertos retirados de ambas as revistas analisadas. Os resultados sugerem que as revistas funcionam como um dispositivo pedagógico que, por meio das práticas linguísticas relacionadas a Pabllo Vittar, nos ensinam modos outros de ser e estar no mundo social.

Palavras-Chave: concepção de língua; binômio masculino-feminino; dispositivo pedagógico

\begin{abstract}
This paper analyses the editions n. 2.192 and n. 137 of Contigo! and Rolling Stone magazines, which were published respectively in September, 2017 and January, 2018. Those magazines introduce linguistic practices related to the singer Pabllo Vittar that seem to desestablish the masculine-feminine binomial, which constitutes what is considered as the Portuguese language. Results suggest that the magazines function as a pedagogical device that, among the linguistic practices related to Pabllo Vittar, teach us other ways of being and living in the social world.
\end{abstract}

Keywords: concept of language; masculinefeminine binomial; pedagogical device

\footnotetext{
1 Mestre em Estudos de Linguagem pelo Programa de Pós-Graduação em Estudos de Linguagem (PPGEL) da Universidade Federal de Mato Grosso (UFMT). E-mail: yure lua@ hotmail.com

${ }^{2}$ Professor do Departamento de Letras e do Programa de Pós-Graduação em Estudos de Linguagem (PPGEL) da Universidade Federal de Mato Grosso (UFMT).E-mail: fernando_vesz@ hotmail.com
} 


\section{Introdução ${ }^{3}$}

Desde seu surgimento ao grande público, a cantora ${ }^{4}$ Pabllo Vittar tem provocado certo furor devido à referência a práticas linguísticas, consideradas do gênero feminino em língua portuguesa, porém empregadas em associação com elementos classificados como pertencentes ao gênero masculino da língua. Assim, comentários como "Causa-me indignação ler que Pablo Vittar é ‘cantora'. Pablo é nome masculino [...] Então é CANTOR”, retirado da revista eletrônica $O$ Tempo ${ }^{5}$, tornaram-se recorrentes em matérias sobre Pabllo Vittar, sobretudo quando revistas e sites enunciam a cantora com elementos femininos.

Desse modo, chamam-nos à atenção que, de modo geral, esses comentários preocupam-se em estabelecer a marcação em relação aos gêneros masculino e feminino, reproduzindo uma concepção binária da língua portuguesa - a exemplo do comentário acima, cujo autor se apresenta contrariado ao deparar-se com textos que se referem a Pabllo, um substantivo próprio masculino, como cantora, em vez de cantor. Para esse leitor, é como se a revista online $O$ Tempo deturpasse a língua, o que parece concorrer para a desrregulação da língua portuguesa, além de promover certa "imundície verbal" (BORBA; LOPES, 2018) em relação ao modo como a língua seria "normalmente" utilizada. Essa inflexibilidade parece relacionar-se com o pensamento arborescente (DELEUZE; GUATTARI, 1997, 2014), que contribui para a construção do binômio masculino-feminino na forma como entendemos a língua portuguesa. Assim, quando observam certos usos que ultrapassam as noções pré-estabelecidas por sistemas binários, os próprios usuários da língua sentem-se obrigados em desempenhar o papel de reguladores ou inquisitores legítimos das leis que regem o sistema de determinada língua.

Neste artigo, analisamos as práticas linguísticas apresentadas em torno da cantora Pabllo Vittar nas edições n. 2.192 e 137 das revistas Contigo! e Rolling Stone, respectivamente, publicadas no período compreendido entre setembro de 2017 e janeiro de 2018. Este recorte se relaciona com o período em que Pabllo Vittar começa a figurar nas capas das referidas revistas, após a participação da cantora no festival de música Rock'n Rio, ocorrido em setembro de 2017, na cidade do Rio de Janeiro, e suas músicas iniciam a ocupar as primeiras posições entre as mais executadas em rádios e

\footnotetext{
${ }^{3}$ Este artigo é um recorte modificado da dissertação de mestrado do primeiro autor, defendida no Programa de PósGraduação em Estudos de Linguagem (PPGEL) da Universidade Federal de Mato Grosso (UFMT), sob orientação do segundo autor.

${ }^{4}$ Em virtude da posição teórica adotada nesta pesquisa, referimo-nos a Pabllo Vittar sempre por meio de elementos classificados como femininos na língua portuguesa.

5 Disponível em: <www.otempo.com.br/diversao/mais-ruim-do-que-eu-diz-cantor-falcao-sobre-pabllo-vittar1.1555436>. Acesso em: 28 set. 2019.
} 
serviços de streaming de música no país. Desse modo, buscamos compreender o posicionamento das referidas revistas sobre como referir-se à cantora Pabllo Vittar, mediante uma concepção de língua vigente ainda regularizada pelo binômio masculino-feminino. Para tanto, lançamos mão, inicialmente, do conceito de dispositivo pedagógico da cultura pop.

\section{Cultura pop e as noções de ser e estar no mundo contemporâneo}

Rotular algo como pop pode muitas vezes caracterizar uma adjetivação desqualificadora, de elementos descartáveis pela mídia, ou, por outro lado, atribuir certo prestígio a itens que estão no auge ou que caíram no gosto popular de determinado grupo social. De acordo com Sá, Carreiro e Ferraraz (2015), em ambos os casos, observa-se a dualidade e as controvérsias que assinalam o termo “cultura pop". Assim, destacam os autores, a cultura pop pode expressar um espaço profícuo para embates, tensões, valores e lutas culturais oriundas de várias vertentes midiáticas, tais como cinema, teatro, fotografia, quadrinhos, plataformas digitais, música e, acrescentaríamos, revistas consideradas como de entretenimento, a exemplo das revistas Contigo! e Rolling Stone. Desse modo, conforme Soares (2015), a cultura pop pode ser compreendida para além do consumo, da histeria momentânea, da frivolidade e do supérfluo: conforme o autor, os produtos da cultura pop podem ajudar a articular novas normas de diferenciação nos contextos contemporâneos.

De maneira similar, porém voltando-se para o campo dos estudos midiáticos, Fischer (2012) destaca o papel da mídia como recurso pedagógico. Segundo a autora, a mídia não apenas veicula informação e/ou entretenimento, mas também tece, “[...] constrói discursos e produz significados e sujeitos" (FISCHER, 2012, p. 113). A autora, portanto, preocupa-se em observar a mídia como “dispositivo pedagógico", ou seja, como agente fomentador de determinadas noções e certos saberes a respeito do mundo social: aprendemos modos de ser e estar no mundo por meio da mídia. Como destaca Fischer, a mídia constitui-se como lócus de educação.

De igual modo, a cultura pop pode exercer "[...] profunda influência no(s) modos(s) como as pessoas experimentam o mundo ao seu redor" (SÁ; CARREIRO; FERRARAZ, 2015, p. 9). Sendo assim, também pode compor-se como dispositivo pedagógico, ou seja, consumir um produto proveniente da cultura pop pode ensinar-nos determinadas maneiras de ser e estar no mundo social, engendrando-se, portanto, como lócus de educação. Por exemplo, ler uma revista como Contigo!, considerada apenas como um artefato cultural destinado ao entretenimento, uma vez que desfila matérias e reportagens sobre famosos e celebridades, pode significar aprender modos outros de ser e estar no mundo. Quando uma edição dessa revista estampa na capa a cantora Pabllo Vittar, sob o 
título “Quem é este fenômeno?", e lança mão do uso de elementos masculinos e femininos em uma mesma frase - “a cantora (ou cantor, já que prefere evitar definição de gênero!)” - a própria revista já parece apresentar-se como um dispositivo pedagógico disposto a questionar uma concepção de língua normatizada pelo binômio masculino-feminino.

\section{A concepção de língua para além do binômio masculino-feminino}

Primeiramente, convém pontuar que, neste artigo, o conceito de língua é tomado como processo de invenção, ou seja, como produto da discursivização “[...] no interior de um dispositivo com fins de gestão e controle de povos e de terras" (SEVERO, 2016, p. 12). Por esse viés, segundo a autora, entende-se língua como fruto de um largo processo de criação, controle e gestão de identidades, que não só garantiram a longevidade de certos sistemas, mas também a supremacia diante de outros. É nesse enquadre sócio-histórico que o paradigma monolíngue se instituiu, contribuindo para a manutenção da concepção de língua como um sistema único, estável e livre de quaisquer influências que fujam das características pré-estabelecidas por suas severas normas.

Tal panorama a respeito da constituição da concepção de língua aproxima-se de um sistema filosófico "arbóreo" (DELEUZE; GUATTARI, 2014), o qual se origina de uma semente - fruto da criação - e se desenvolve hierarquicamente por suas raízes, troncos, galhos e frutos. Os autores constroem essa metáfora baseada na ilustração de uma árvore, que funciona principalmente para explicar determinada perspectiva de pensamento delineada sob a necessidade de "uma forte unidade principal, unidade que é suposta para chegar a duas" (DELEUZE; GUATTARI, 2014, p. 20). Sendo assim, a imagem da árvore-raiz atua de acordo com uma lógica binária, que "não para de desenvolver a lei do Uno que devém dois, depois dois que devêm quatro...” (DELEUZE; GUATTARI, 2014, p. 20). Nesse sistema linear, conforme proposto pelos autores, prevalece uma lógica binária, que se refere metaforicamente ao produto originário de um "tronco" que insistentemente se bifurca em ramos específicos. No pensamento arborescente, portanto, há apenas uma linearidade composta por propósitos binários e hierárquicos.

Ainda segundo os autores, esse sistema arbóreo “[...] dominou toda a realidade ocidental e todo o pensamento ocidental, da botânica à biologia, a anatomia, mas também a gnosologia, a teologia, a ontologia, toda a filosofia... o fundamento raiz" (DELEUZE; GUATTARI, 2014, p. 2829). A concepção de língua não passou incólume a todo esse processo. De acordo com Deleuze e Guattari (1997), a língua, no pensamento arborescente, define-se, sobretudo, por um conjunto de ligações com posições fixas, derivadas de uma lógica binária, tais como as conhecidas bases duais da 
gramática normativa: masculino-feminino, singular-plural, substantivo-verbo etc. Isso resultou, segundo Lima e Borba (2016), em determinado tipo de saber que considera apenas duas possibilidades válidas, excluindo e apagando todo e qualquer cenário que escape às duas primeiras proposições. Em relação à concepção de língua, há a instituição de apenas duas possibilidades de gênero para os substantivos, vinculadas à chamada questão lexical das palavras: mulher = feminino e homem = masculino.

Entretanto, como observam Borba e Lopes (2018), os gêneros masculino e feminino não estão relacionados única e exclusivamente a essa suposta natureza lexical, mas atrelados a questões sociais, como é o caso, em língua portuguesa, dos substantivos dotados de um "masculino genérico" para se referir à humanidade como um todo. Este fato, advertem os autores, é tido assim como um "simples fenômeno linguístico e não como um produto de convenções sociais e políticas de sociedades patriarcais" (BORBA; LOPES, 2018, p. 17), entendido muitas vezes como "imundície verbal”, que apenas serve para desestabilizar e "sujar" a língua portuguesa - a exemplo do incômodo do leitor sobre o emprego do substantivo "cantora" em referência a Pabllo Vittar, no comentário retirado da revista eletrônica $O$ Tempo, com o qual abrimos a introdução deste artigo. Lima e Borba (2016) pontuam que a causa de tal desconforto parece estar vinculada ao aparecimento de práticas linguísticas que rompem com o ideal de estabilidade e pureza prescrito pelo paradigma monolíngue.

Como nos lembra Butler (2003), o gênero não é natural, mas socialmente construído. Nesse sentido, destaca a autora, as práticas linguísticas atuam como atos repetidos de resultados "consolidados" que ajudam a constituir a acepção do que é homem e do que é mulher. Em contrapartida, essa mesma perspectiva levanta questionamentos em relação aos possíveis apagamentos e/ou exclusões de identidades díspares, diferentes das que não contemplam o ideal de feminino ou de masculino reafirmados pela linguagem, extrapolando as normatividades para além do binômio masculino-feminino, favorecendo uma abertura de "olhar e das sensibilidades a outras estéticas que desafiam e desnaturalizam hierarquias classificatórias e relações de poder" (LIMA; BORBA, 2016, p. 113). É esse olhar que as revistas Contigo! e Rolling Stone parecem lançar quando estampam a cantora Pabllo Vittar nas capas das edições aqui em análise, constituindo-se como loci de educação.

\section{Procedimentos metodológicos}

Para construção e análise do corpus deste trabalho, adotou-se o método de pesquisa qualitativa, uma vez que possibilita ao pesquisador um "conjunto de práticas materiais e 
interpretativas que dão visibilidade ao mundo" (RAMALHO; RESENDE, 2011, p. 76), por meio das quais o pesquisador poderá descrevê-lo, interpretá-lo e entendê-lo. Assim, como pontuam Ramalho e Resende (2011), obtém-se uma pesquisa em que o pesquisador é "guiado por um conjunto de crenças e de sentimentos em relação ao mundo e ao modo como este deveria ser compreendido e estudado" (RAMALHO; RESENDE, 2011, p. 74). Dentro dessa perspectiva, lançamos mão da pesquisa documental para a construção do corpus, no intento de definir "estratégias para gerar dados que ajudassem a alcançar os objetivos pretendidos e a responder às questões da pesquisa" (RAMALHO; RESENDE, 2011, p. 95).

Desse modo, o corpus, composto por quinze excertos das revistas Contigo! e Rolling Stone, busca analisar as práticas linguísticas empregadas por essas revistas para referir-se à cantora Pabllo Vittar. Para tanto, verifica-se, em cada excerto, três aspectos: (1) o emprego de comentários elucidativos a respeito do uso concomitante dos gêneros masculino e feminino em referência a Pabllo Vittar, (2) a naturalização de tal uso, sem a necessidade de qualquer explicitação sobre tal concomitância, e (3) o privilégio de formas femininas para se referir à cantora.

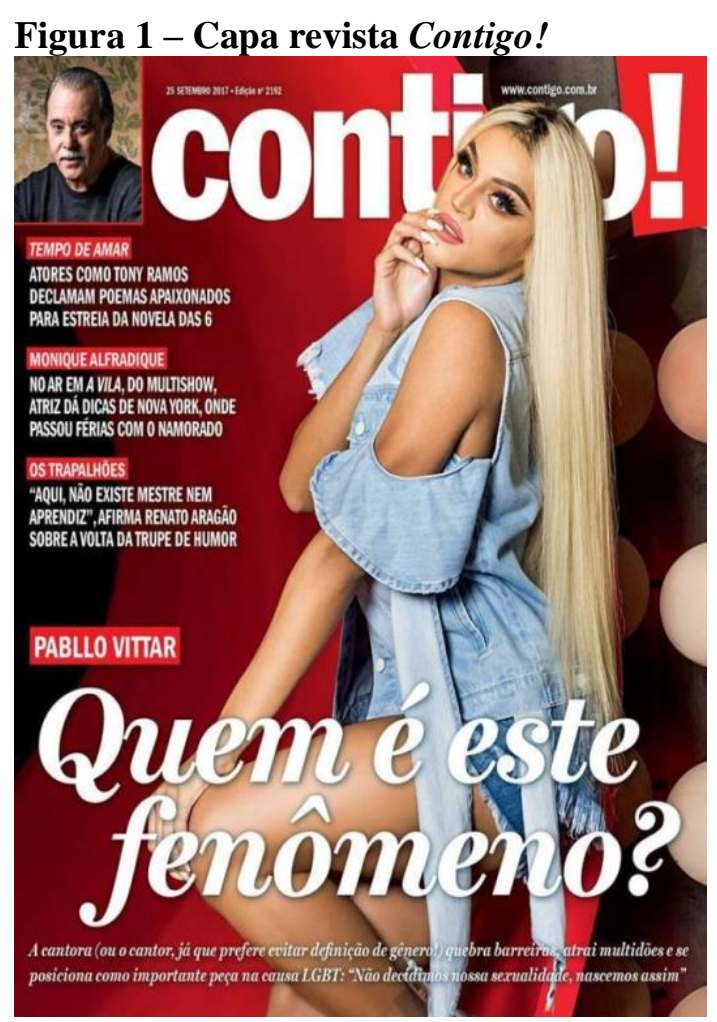

Revista Contigo! - edição n. 2192 (25 de setembro de 2017)
Figura 2 - Capa revista Rolling Stone

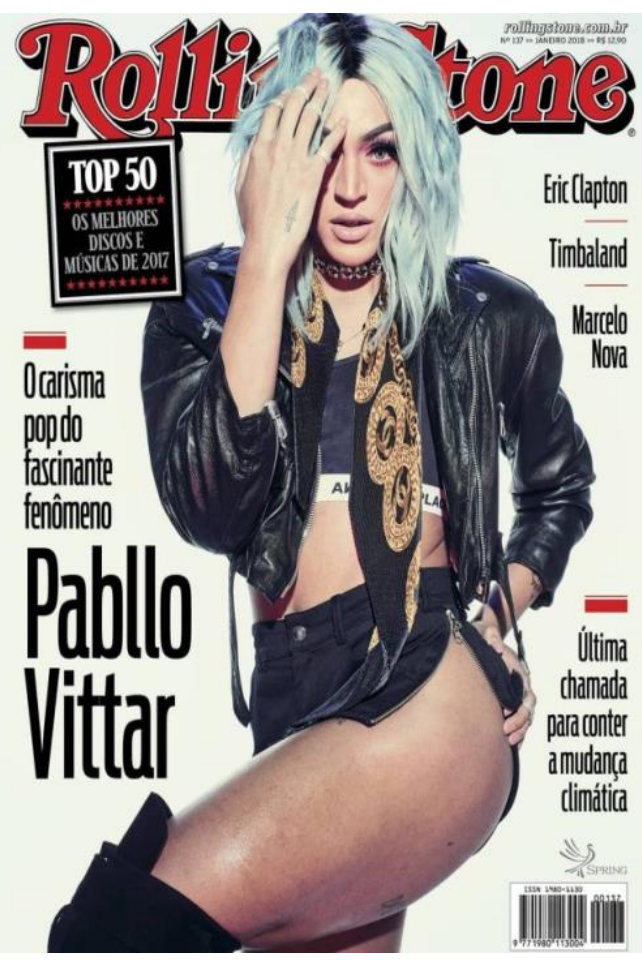

Revista Rolling Stone - Edição n. 137 (janeiro de 2018) 


\section{As práticas linguísticas relacionadas a Pabllo Vittar na Revista Contigo!}

A primeira revista em que Pabllo Vittar aparece como capa é a Contigo!, publicada em 25 de setembro de 2017, logo após a cantora se apresentar no festival Rock'n Rio daquele ano, causando bastante repercussão.

\section{Quadro 1 - Excertos da revista Contigo!}

\begin{tabular}{|c|}
\hline Excertos destacados: \\
\hline $\begin{array}{l}\text { 1. "A cantora (ou o cantor, já que prefere evitar definição de gênero!) quebra barreiras, atrai } \\
\text { multidões e se posiciona como importante peça na causa LGBT: "não decidimos nossa } \\
\text { sexualidade, nascemos assim" }\end{array}$ \\
\hline 2. "Produção sempre assinada por ela (ou por ele, já que artigos não a definem)" \\
\hline $\begin{array}{l}\text { 3. "Muitas vezes, você se chama no masculino, e outras, no feminino... Depende de que, estado } \\
\text { de espírito? - Artigo para definir pessoas é tipo marcar boi, sabe? A gente é livre para ser o } \\
\text { que quiser e eu sou 'o' ou 'a'. Não será uma letra que definirá meu gênero ou quem eu sou" }\end{array}$ \\
\hline 4. "Apesar de ter uma equipe, sua produção é feita por ela" \\
\hline 5. "[...] foi convidada para ser empresariada" \\
\hline 6. “venerada pelo público" \\
\hline 7. "Solteira, ela brinca $[\ldots] "$ \\
\hline $\begin{array}{l}\text { 8. "Fiquei muito honrado, somos grandes amigas (elelela se refere sempre a si mesmo/a } \\
\text { alternadamente) [...]" }\end{array}$ \\
\hline
\end{tabular}

O primeiro excerto a ser analisado, “A cantora (ou o cantor, já que prefere evitar definição de gênero!) quebra barreiras, atrai multidões e se posiciona como importante peça na causa LGBT: 'não decidimos nossa sexualidade, nascemos assim"”, aparece como resposta à pergunta que intitula a capa da edição - "Pabllo Vittar, quem é este fenômeno?" O uso de elementos masculinos e femininos em uma mesma frase - "a cantora (ou cantor...)" - ocorre, a nosso ver, por dois motivos: o primeiro parece estar relacionado à necessidade inicial da revista em apresentar e explicar em que consiste a figura apresentada, uma vez que se trata da primeira revista a vincular, em sua capa, uma artista a qual aceita ser mencionada tanto por elementos femininos como por elementos masculinos; o segundo, decorrente do primeiro, refere-se ao caráter também pedagógico de uma revista como a Contigo!, especializada em retratar a vida de famosos e de celebridades. Como observa Fischer (2012), a preocupação apresentada pela mídia não se vincula apenas a entreter ou a oferecer notícias, mas também se posicionar "como lócus de educação, de formação, de condução da vida e de como esse fato tem importantes repercussões nas práticas sociais" (FISCHER, 2012, p. 113). Nesse sentido, o subtítulo da capa, “a cantora (ou o cantor, já que prefere evitar definição de gênero!)” se encarrega 
em retomar e explicar as questões que circundam a figura de Pabllo Vittar - uma artista, que possui um nome masculino, mas que aceita ser tratada tanto como cantor quanto como cantora.

Sob essa perspectiva, observa-se uma matéria dividida em dois momentos: no primeiro, constante inicialmente da capa da revista, parece haver a preocupação em explicar e definir o emprego concomitante dos gêneros masculino e feminino para se referir a Pabllo Vittar; no segundo instituídas as devidas explicações -, a livre utilização de elementos masculinos e femininos em uma mesma frase. Isso ocorre, a nosso ver, porque inicialmente se torna preciso explicar como uma cantora, a qual apresenta um nome masculino, se apropria de elementos linguísticos que transitam pelo binômio masculino-feminino com a finalidade de construir sua performance artística. Ademais, tal explicação consolida as escolhas linguísticas apresentadas pela revista no decorrer da matéria.

No excerto subsequente da matéria, a não regularidade do uso e concordância com o gênero é retomada no excerto "Produção sempre assinada por ela (ou por ele, já que artigos não a definem)", constante do parágrafo de introdução da entrevista. Tal excerto, além de resgatar o caráter pedagógico apresentado no subtítulo da capa da revista, relaciona-se, em particular a explicação entre parênteses, com a resposta da terceira pergunta da entrevista: "Muitas vezes, você se chama no masculino, e outras, no feminino... Depende de que, estado de espírito?" A resposta dada pela cantora ganha ênfase na página seguinte - "Artigo para definir pessoas é tipo marcar boi, sabe? A gente é livre para ser o que quiser e eu sou 'o' ou 'a'. Não será uma letra que definirá meu gênero ou quem eu sou” -, retomando o caráter pedagógico que a revista, por ser a responsável em apresentar Pabllo Vittar ao grande público, parece assumir, em particular no que se refere à preocupação em explicar e definir o emprego concomitante dos gêneros masculino e feminino para aludir à cantora.

Portanto, dado o devido destaque, uma vez mais, à explicação sobre as práticas linguísticas relacionadas a Pabllo Vittar, a revista parece ampliar seu posicionamento em relação a não normatividade em concordar elementos masculinos com masculinos, ou femininos com femininos. Sempre se referindo a Pabllo Vittar no gênero feminino, tal premissa pode ser constatada nos excertos 4, 5, 6 e 7: "Apesar de ter uma equipe, sua produção é feita por ela”, “[...] foi convidada para ser empresariada", "venerada pelo público" e "Solteira, ela brinca [...]”, os quais compõem legendas de fotos e perguntas da entrevista. De igual modo, quando a cantora se refere a si mesma durante a décima segunda pergunta da entrevista - "Anitta quis te empresariar e você recusou. Isso gerou algum ruído na relação de vocês?" - a coexistência entre elementos masculinos e femininos no excerto que constitui o início da resposta à pergunta - "Fiquei muito honrado, somos grandes amigas (elelela se refere sempre a si mesmo/a alternadamente) [...]", bem como a retomada, constante entre parênteses e em itálico, da explicação do emprego conjunto dos gêneros masculino e feminino para remeter a 
Pabllo Vittar, parece recuperar a análise das práticas linguísticas sobre a cantora desenvolvidas ao longo desta primeira seção.

\section{As práticas linguísticas relacionadas a Pabllo Vittar na revista Rolling Stone}

Importante publicação nas áreas da música e da cultura pop, a revista Rolling Stone, edição publicada em janeiro de 2018, cuja matéria de capa intitula-se "O carisma pop do fascinante fenômeno Pabllo Vittar”, parece caminhar para a naturalização, sem qualquer indício de necessidade de alguma elucidação, a respeito do emprego simultâneo dos gêneros masculino e feminino quando a matéria reporta-se a Pabllo Vittar: a revista parece sentir-se "muito à vontade" para empregar elementos femininos, mesmo referindo-se a um nome artístico na forma masculina, sem qualquer necessidade de alguma adenda que vise a explicar tal uso.

\section{Quadro 2 - Excertos da revista Rolling Stone}

\begin{tabular}{|l|l|}
\hline Excertos destacados: \\
\hline 1. & "[...] onde fica o estúdio em que ela gravaria algumas horas depois. A cantora sacou um celular \\
para trilhar o nosso encontro e ela mesma ficou surpresa ao ouvir que uma faixa sua estava ali \\
naquela playlist. Desmontada, com os cabelos curtos à mostra e calçados chinelos, ela sai mais \\
tímida [...]"
\end{tabular}

Nos excertos destacados acima, apesar de todos referirem-se a Pabllo Vittar, a revista Rolling Stone alude à cantora sempre no gênero feminino - desde o excerto 1, constante do parágrafo que abre a reportagem, até o excerto 7, encontrado na penúltima página da reportagem, registram-se cinco ocorrências do pronome pessoal "ela" (nos excertos 1, 3 e 4), bem como uma ocorrência da forma 
contraída "dela" (no excerto 2) na função de pronome possessivo, e outra ocorrência do pronome oblíquo "a" (no excerto 3). Além disso, o substantivo "cantora" é empregado três vezes (nos excertos 1, 2 e 6) e o adjetivo "brasileira" consta em dois dos excertos (5 e 7). Sobre adjetivações, sempre que usadas em menção a Pabllo Vittar, são registradas no feminino, como "desmontada", nos excertos 1 e 6, "desconhecida" e "abalada", ambas no excerto 3, "cansada", no excerto 6, e "seguida", no excerto 7. Esse traço acerca do predomínio do gênero feminino para referir-se à cantora não requer a necessidade do selo de esclarecimento sobre a primazia das referências a Pabllo Vittar no feminino a revista sente-se "muito à vontade" para utilizar elementos femininos em referência a um nome artístico que se apresenta na forma masculina.

Nesse andar, o emprego dos sintagmas "uma Pabllo", no excerto 3, e "uma Pabllo Vittar", no excerto 6, parecem convergir para esse entendimento da revista Rolling Stone apresentado no final do parágrafo anterior, ou seja, a comodidade da revista em empregar o pronome indefinido "uma" acompanhando o substantivo próprio "Pabllo (Vittar)". Considerando que "Pabllo" é um substantivo próprio "masculino", o posicionamento da revista parece flutuar para além das noções de feminino e de masculino, conectando elementos linguísticos que não parecem obedecer à ordem binária preestabelecida na língua portuguesa, conforme destacada por Deleuze e Guattari (1997). Em outras palavras, dilui a concordância de gênero que tal construção linguística demandaria, ou ainda, o próprio binômio masculino-feminino que organiza e estrutura nosso entendimento acerca de concordância nominal entre pronome e substantivo. Esse posicionamento parece conduzir a outro entendimento sobre o caráter pedagógico da cultura pop, observado, ainda que em grau diferente, na análise precedente da revista Contigo! - sem a necessidade de explicar esses usos linguísticos, mas de certa forma naturalizando-os, empregando-os sem a obrigação de qualquer comentário elucidativo em relação a esses usos. É nesse clima de não demarcação binária do gênero, de alternância entre as formas masculina e feminina, mas também privilegiando as formas femininas para se referir a Pabllo Vittar, que ambas as revistas aqui analisadas parecem contribuir para o (re)dimensionamento do binômio masculino-feminino constituinte da concepção de língua.

\section{Considerações finais}

Neste artigo, analisamos as práticas linguísticas relacionadas à cantora Pabllo Vittar nas edições n. 2.192 e 137 das revistas Contigo! e Rolling Stone, respectivamente, publicadas no período compreendido entre setembro de 2017 e janeiro de 2018, de modo a compreender o posicionamento das referidas revistas sobre como referir-se à cantora Pabllo Vittar, mediante uma concepção de língua 
pautada pelo paradigma monolíngue (e suas características pré-estabelecidas por severas normas), herdeiro do pensamento arborescente, com suas posições fixas e sua lógica binária, o qual contribui para o apagamento e/ou a exclusão de quaisquer influências que fujam de suas características "naturais", rotulando-as como "imundície verbal" que apenas serve para desestabilizar a língua portuguesa e suas bases duais.

O posicionamento das revistas aqui analisadas parece reafirmar o caráter pedagógico da cultura pop para além do consumo, da frivolidade e do supérfluo: seja por meio de comentários elucidativos a respeito do uso concomitante dos gêneros masculino e feminino para se referir à cantora Pabllo Vittar, seja naturalizando tal uso, sem a necessidade de qualquer explicitação sobre tal concomitância, ou ainda privilegiando as formas femininas para se referir a Pabllo Vittar, ambas as revistas parecem contribuir para o (re)dimensionamento do rígido binômio masculino-feminino constituinte da língua portuguesa. De fato, conforme abordamos em outro passo, aprendemos modos outros de ser e estar no mundo por meio da cultura pop, ou, como diria a própria Pabllo Vittar na entrevista para a revista Contigo!, “a gente é livre para ser o que quiser e eu sou 'o' ou 'a'. Não será uma letra que definirá meu gênero ou quem eu sou". Talvez ler revistas consideradas apenas como “de entretenimento" possa apresentar um caráter pedagógico mais condizente com os tempos atuais.

\section{Referências}

BORBA, R; LOPES A. C. Escrituras de gênero e políticas de différance: imundície verbal e letramentos de intervenção no cotidiano escolar. Linguagem \& Ensino, v. 21, 2018, p. 241-285.

BUTLER. J. Problemas de gênero: feminismo e subversão da identidade. Rio de Janeiro: Civilização Brasileira, 2003.

DELEUZE, G.; GUATTARI, F. Mil platôs - capitalismo e esquizofrenia, vol. 2. Trad. Ana Lúcia de Oliveira e Lúcia Cláudia Leão. São Paulo: Ed. 34, 1. ed., 2. reimp., 1997.

DELEUZE, G.; GUATTARI, F.. Introdução: rizoma. In: DELEUZE, G.; GUATTARI, F. Mil platôs - capitalismo e esquizofrenia, vol. 1. Trad. Aurélio Guerra Neto. São Paulo: Ed. 34, 2. ed., 1. reimp., 2014, p. 17-49.

FISCHER, R. M. B. Trabalhar com Foucault: arqueologia de uma paixão. Belo Horizonte: Autêntica, 2012. 
LIMA, F.; BORBA, R. Sobre (des)aprendizagem e multidões queer: rizomas, multiplicidades e a política menor. In: ALVES, D. S. (Org.). Gênero e diversidade sexual: teoria, política e educação em perspectiva. Tubarão: Copiart, 2016, p. 79-114.

RAMALHO, V.; RESENDE, V. M. Análise de discurso (para a) crítica: o texto como material de pesquisa. Campinas: Pontes, 2011.

SÁ, S. P.; CARREIRO, R. FERRARAZ, R. (Orgs.). Cultura pop. Salvador: EdUFBA, 2015.

SEVERO, C. G. A invenção colonial das línguas da América. Alfa, São Paulo, v. 1, p. 11-28, 2016.

SOARES, T. Percursos para estudos sobre música pop. In: SÁ, S. P.; CARREIRO, R. FERRARAZ, R. (Orgs.). Cultura pop. Salvador: EdUFBA, 2015, p. 19-33. 